ENCYCLOPEEDIE Encyclopédie berbère

BERBERE

9 | 1991

9 | Baal - Ben Yasla

\title{
Belgassem Ngadi
}

(Belkacem N'Gadi)

M. Peyron

\section{CpenEdition}

Journals

Édition électronique

URL : http://journals.openedition.org/encyclopedieberbere/1512

DOI : $10.4000 /$ encyclopedieberbere.1512

ISSN : 2262-7197

\section{Éditeur}

Peeters Publishers

\section{Édition imprimée}

Date de publication : 1 avril 1991

Pagination : 1434-1435

ISBN : 2-85744-509-1

ISSN : $1015-7344$

Référence électronique

M. Peyron, «Belgassem Ngadi », Encyclopédie berbère [En ligne], 9 | 1991, document B55, mis en ligne le 01 avril 2013, consulté le 24 septembre 2020. URL : http://journals.openedition.org/ encyclopedieberbere/1512 ; DOI : https://doi.org/10.4000/encyclopedieberbere.1512

Ce document a été généré automatiquement le 24 septembre 2020.

(c) Tous droits réservés 


\section{Belgassem Ngadi}

\section{(Belkacem N'Gadi)}

\section{Peyron}

1 Aventurier, se faisant passer pour cherif, qui a profité d'une situation confuse, née de la résistance dans le Sud-Est marocain, pour s'emparer du Tafilalt (1919-1932).

2 Né vers 1875-1880, natif de la plaine des Angad, Belqassem se réclamait des Ouled Sidi Belqassem Azeroual (Spillman, 1936), chorfa idrissides dont une des zawiya-s se trouvait à Taforalt (Bni Iznassen). Son penchant pour l'aventure se signale de bonne heure lorsqu'il se rallie au prétendant Bou-Hamara (Bū-Ḥmāra) dans la région de Taza. Il s'installe par la suite au Tafilalt en 1917, et se met au service d'un chef local, faux cherif lui aussi, Moha n-Ifrouten, qui lui confie le commandement de sa petite armée (harka). La chance lui sourit le 9 août 1919, au combat de Gaouz, qui voit l'armée française se replier provisoirement sur Erfoud. Entre temps, Belqassem, dont le pouvoir ne cesse de grandir, a fait éliminer deux chefs spirituels de la région en qui il voyait des rivaux potentiels. En octobre 1919, lors d'une expédition contre le poste d'Erfoud, il assassine Moha n-Ifrouten et impose dès lors son autorité despotique au Tafilalt.

3 Accepté par les uns comme champion de l'Islam contre les irrumiyn, contesté par d'autres Filala ne voyant en lui qu'un tyran et un usurpateur, Belqassem se fit respecter par ceux-ci et craindre par ceux-là en sévissant sans pitié contre ses ennemis. Il avait mis en place un pseudo-makhzen autour de la forteresse de Rissani, sur laquelle veillait sa garde prétorienne, composée, pour la plupart, de gens de sac et de corde (Bordeaux, 1931). Cette situation devait durer douze années, ponctuées par des abus et exactions de tout genre, ainsi que par de nombreux coups de main montés contre les postes français du voisinage par des bandes armées pour lesquelles le Tafilalt était devenu un repaire inviolable.

4 C'est le 15 janvier 1932, après bien des atermoiements (Bordeaux, 1935), que le commandement militaire français décide d'en finir avec Belqassem. Dès la première attaque, entouré de ses fidèles, il s'échappe vers le Sud-Ouest. Une tentative pour se maintenir dans le Ktaoua ayant échouée, Belqassem est contraint à se réfugier dans la basse vallée du Dra, puis sur l'Oued Noun, à la limite du Rio de Oro. C'est là qu'il fera sa 
soumission en mars 1934, lors de la fin de la résistance armée dans cette région, avant d'être envoyé en résidence surveillée dans la région d'Oujda (Saulay, 1985).

De tous les chefs de la résistance du Sud-Est marocain, Belqassem est sans conteste celui que les chroniqueurs de l'époque ont le moins ménagé. Décrit comme petit, maigre, avec un visage émacié que mange une barbiche noire, et d'où émergent des yeux perçants, sa démarche claudicante lui vaut le surnom de bellarj (cigogne), alors que dans son dos, en raison de son parler nasillard, on le traite de mangan (Bordeaux, 1931). On le dit, par ailleurs, attaché aux pratiques religieuses et marié, mais on ne lui connaît pas de descendance. A vrai dire, ce sont plutôt ses défauts que l'on énumère : personnage complexe, veule et versatile, à la fois opportuniste et tyranneau de village, tour à tour homme de terrain et intrigant mesquin, qui, en éliminant impitoyablement tous ses rivaux, réussit à faire le vide autour de lui.

En contrepartie, si Belqassem était, certes, un aventurier, il ne faut pas oublier que l'époque trouble où il vécut était propice à l'apparition de "Maitres de l'Heure ", de rogui-s, de tout acabit. Quant à son rôle de résistant, même s'il n'avait à cœur que son intérêt personnel, nul ne peut nier sa contribution sur le terrain. Par sa mainmise sur le Tafilalt (1919-1932), gîte d'étape du commerce caravanier et prestigieux berceau dynastique transformé en place forte ; par l'appui effectif dont il bénéficiait de la part des contingents Ayt Khebbaš et Ayt Ḥammu, fer de lance de la dissidence, qui rayonnaient dans toute la région; par la menace permanente qu'il faisait peser sur les communications françaises dans la zone des confins algéro-marocains; par un certain charisme émanant de sa personne, doublé du prestige que lui conférait ce semblant de gouvernement qu'il avait créé à Rissani. En somme, quelle que fut sa valeur morale, un ensemble de circonstances concourait, en ces temps-là, pour faire de Belqassem le porte-drapeau de la résistance dans le Sud-Est marocain.

\section{BIBLIOGRAPHIE}

BORDEAUX H., Un printemps au Maroc, Paris, Plon, 1931, p. 106-110.

BORDEAUX H., Henry de Bournazel, Paris, Plon, 1935, p. 266-271.

JANON R., Pillafort, Casablanca, Fontana, 1948, p. 74-95.

SAUlay J., Histoire des Goums marocains, t. 1, Paris, La Koumia, 1985, p. 280-282, etc.

SPILlmAN G., Les Aït Atta du Sahara et la pacification du Haut Dra, Rabat, F. Moncho, 1936, p. 99-101.

VOINOT L., Sur les traces glorieuses des pacificateurs du Maroc, Paris, Charles Lavauzelle, 1939, p. 255, etc.

\section{INDEX}

Mots-clés : Biographie, Maroc 